\title{
IJUH
}

The International Journal of Urologic History ( www.ijuh.org

\section{Was President Andrew Jackson Overcharged? An Economic Evaluation of 19th Century Surgical Charges for Urologic Procedures and their Comparison to the Modern, RVU Era}

\author{
Vincent J. Wong*, Ashley Dixon, Sean Fullerton, Erin Grantham \\ From the Department of Urology (VJW, AD, SF) Westchester Medical Center, New York Medical College, Valhalla, New York and \\ the Department of Urology (EG), Billings Clinic, Billings, MT \\ *Correspondence: Department of Urology, 19 Skyline Drive 1S-B48, Valhalla, New York; e-mail: : vjcwong@gmail.com
}

\begin{abstract}
Introduction: Surgical billing is as old as the profession of surgery but there is no published data that has characterized changes in surgical fees over history. Surgical remuneration has been better studied in the Medicare era of relative value units (RVUs)-based payment but what surgeons charged in the American 18th and 19th centuries is unknown. President Andrew Jackson underwent surgery by Dr. James Hall for a hydrocele in 1832 and was billed, and then paid, $\$ 30$. Our initial objective was to determine the appropriateness of Dr. Hall's surgical billing for that era. We then wished to determine historical trends in physician billing for similar urologic procedures in the 18th-19th centuries compared to the current RVU era, correcting for inflation.
\end{abstract}

Sources and Methods: Published fee tables from 18th and 19th century regional medical societies, prevailing charge data from the Center for Medicare Services (CMS) from 1967-1985, and published RVU values and conversion numbers from 1992-2020 (CMS) were used for analysis. To correct for inflation, we used a published consumer price index (CPI) for 1774-2020 indexed to 2020 US dollars. Mann-Whitney U-tests were used to compare unpaired differences without parametric assumptions.

Results: A total of 43 fee tables from 18 states from 1818-1898 were identified. The $\$ 30$ charge to President Jackson for hydrocele surgery was similar to other states' medical society recommendations of the early 1830s. Over the 19th century, there was an insignificant increase in the low-end fee pricing for hydrocele surgery of $\$ 18.4+/-17.9$ in $1818-1840$ versus $\$ 28.70$ $+/-36.83$ from 1880-1890 ( $p$.05), adjusting for inflation. Similarly, for initial male urinary catheterization, the mean surgical fee of $\$ 4.28+/-1.25$ in 1818-1850 was similar to the $\$ 4.75+/-5.62$ mean surgical fee in 1851-1900 ( $p>.05$ ). Adjusting to 2020 dollars, however, reimbursement for urinary catheterization in 1818-1850, 1850-1900, 1975-1984, and 1992-2020 was $\$ 113.04$ +/- 38.06, $\$ 131.20+/-169.53, \$ 73.87+/-2.38$, and $\$ 23.05+/-4.69$, respectively $(p<.01)$. of $11 \%$.

Conclusions: Dr. James Hall, physician to 10 US Presidents, appropriately billed the 7th President for what would be now described as a hydrocele drainage and scarification. Fees for that procedure remained stable or decreased throughout the 19th century. Surgical fees for male urinary catheterization, however, decreased $82 \%$ from the 1840 s to the 2020 s, correcting for inflation.

Keywords: Surgical Fees; Hydrocele; Historical Trends; Andrew Jackson; James C. Hall

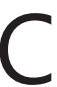
ontemporary methods to reimburse surgical care are derived from the 1985 model of relative value units (RVUs) by Hsiao et al. in which final physician payment is based on a measurement of relative work, expense, and risk of any particular procedure.(1) Hsiao's RVU system was enacted by CMS in 1992 in an attempt to reign in medical costs at a time when physician reimbursement was largely derived from physicians' self-stated "usual, customary, and reasonable" fee.(2) Such fees were, in turn, derived from regional and national medical society guidelines and discretionary surgical billing, a practice which had been in place since the dawn of the American republic.(3) There has been no published data, however, on the exact pricing of specific procedures in the preMedicare era, or from any era, which may illustrate differences in society guided surgical pricing and modern RVU based payments.

The Library of Congress has preserved the medical bills of Dr. James C. Hall of Washington D.C. for services rendered to the 7th US President Andrew Jackson (Figure 
1), for the care and treatment of a hydrocele in the 1830s (Figure 2)(4). Additional care rendered to Jackson, included a second hydrocele operation September 4th, 1833, and subsequent consultations from 1834-1836, and were all billed and reimbursed at similar rates (data not shown). These fragments demonstrate an early 19th century fiduciary relationship between physician and patient. It is unknown, however, if those charges reflect prevailing contemporary billing practices or an inflated, discretionary charge. Dr. Hall's medical billing may serve as more than just a curious memento of Presidential history by acting as a data point in a fuller analysis of similar urologic procedures during the 19th century and beyond. We wished, therefore, to document prevalent billing practices and their costs during the dawn of American surgery for specific urologic procedures. We then aimed to use economic models to compare those 19th century surgical prices with more contemporary data of the RVU era to determine the net change in physician reimbursement over the 200 year period of the Republic.

\section{SOURCES AND METHODS}

Surgical Fee Tables. Surgical fee tables were accessed from 1800-1930 from publicly available digital resources of the University of Missouri Libraries Prices and Wages

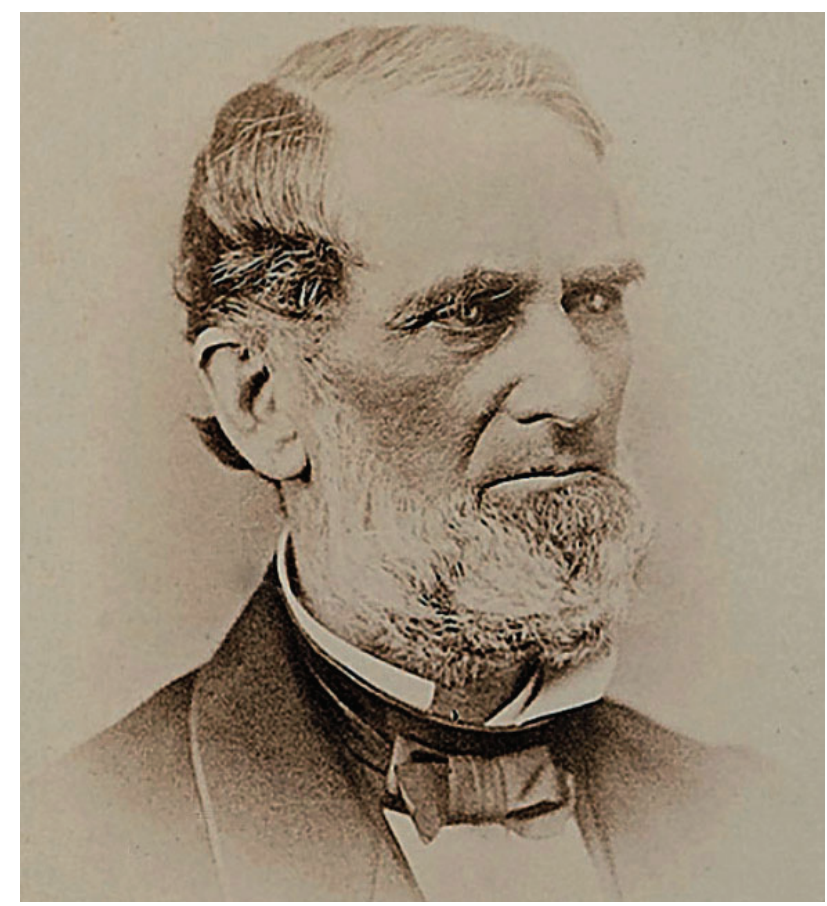

project. Medicare era charges were obtained from the Resource Library of the Center for Medicare Services (www.cms.gov), WorldCat.org, and HathiTrust Digital Library (Ann Arbor, MI).

Consumer Price Index (CPI). CPI conversion factors for dollars for 1774 to estimated 2028 were derived from the tables published by Sahr RC et al., School of Public Policy, Oregon State University (Corvallis).

\section{Relative Value Units (RVU) and Conversion Factor} calculations. We obtained RVUs from 1992-2020 from the Center for Medicare Services, and Conversion Factors from the American Academy of Pediatrics5,6. Physician reimbursement for specific procedures was calculated as the product of the RVUs $x$ the conversion factor for each specific year(5-7). We used the CMS CPT code 51701 for urinary catheterization.

Statistical Considerations. Mann-Whitney U-tests were used to compare unpaired data with non-parametric assumptions using an alpha of 0.05 .

\section{RESULTS}

19th century definitions of "radical cure" for hydrocele. We found that there were two methods

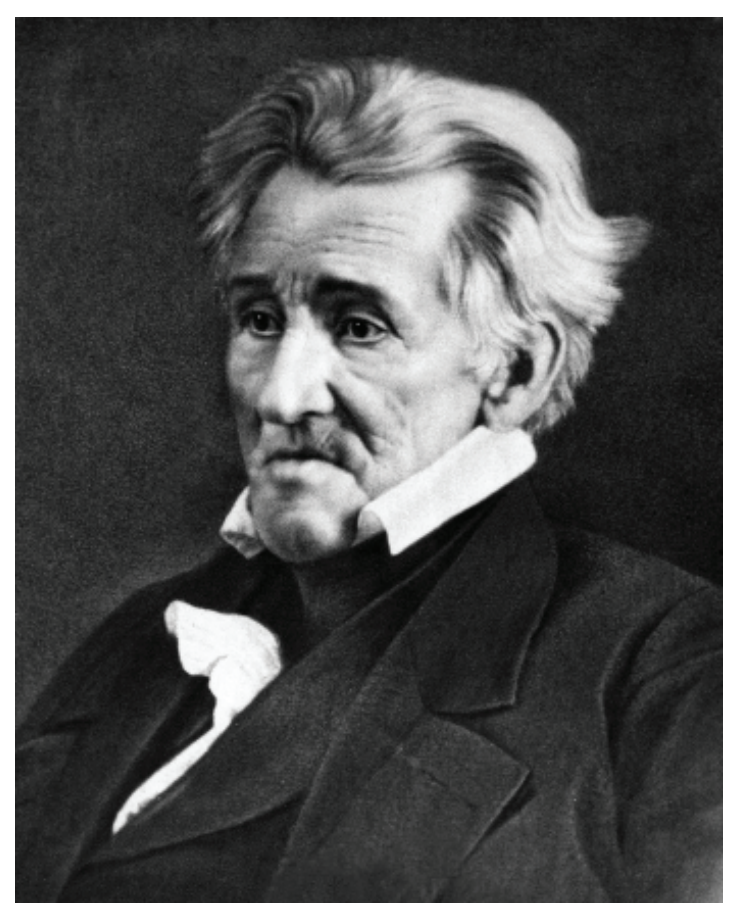

Figure 1. (Left) James Crowdhill Hall, MD (1805-1880), President Andrew Jackson's physician (National Archives, Washington DC); (Right) Daguerrotype of Jackson, April 1845, age 78, by Matthew Brady (WikiMedia Commons, Public Domain) 
for the treatment of a hydrocele in the 19th century and these methods varied vastly from what is commonly referred to now as a "hydrocelectomy". The British surgeon Percivall Potts (1714-1788) appears to have been one of the earliest writers to note that mere drainage of a hydrocele was associated with recurrence and that stringent or sclerosing agents were required to induce the necessary scar formation within planes termed the 'serosal' and 'parietal' layers of the tunica vaginalis. Potts termed the method of induced scarification as a "radical cure".(8) For this reason, there were two types of surgical procedures incorporated into the lexicon as the basis for medical fees: a simple hydrocele drainage or 'puncture' procedure versus hydrocele drainage with the addition of scarifying agents, surgical placement of a through-and-through wick, or placement of a scarifying drain which Pott's termed a "seton". The procedure with these surgical steps appears to have been termed an "operation for hydrocele", "radical cure for hydrocele", "injection of hydrocele", or "radical operation" throughout the 19th century. It was not until the work of Ernst Van

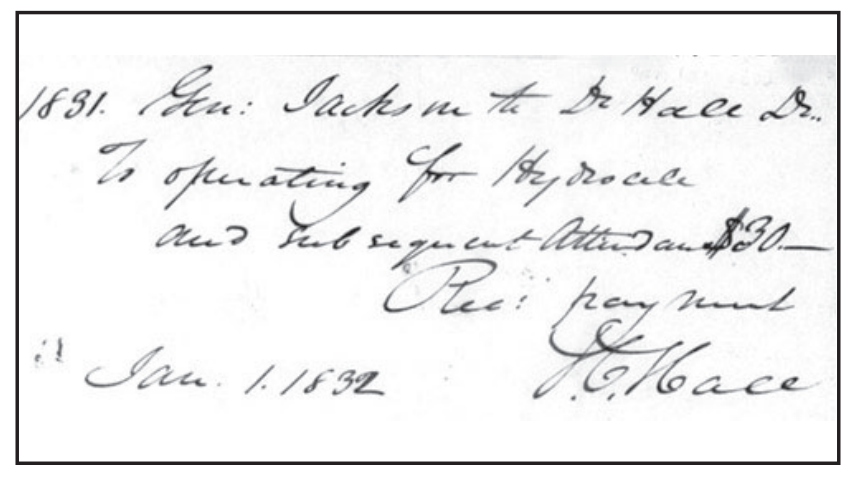

Figure 2. Medical receipt, 1832 , "Gen. Jackson to Dr. (JC) Hall for "operating for Hydrocele and Subsequent Attendance, \$30" (Library of Congress, Andrew Jackson Papers)

Bergmann (in the mid 1860s that led to the technique that the modern urologist would recognize as a true "hydrocelectomy", the operation whereby the excess tunica vaginalis is surgically resected and the edges oversewn (coined the 'Van Bergmann's' procedure at that time). The exact date or time when the Van Bergmann hydrocelectomy became standard of care is unknown but is referenced in the American surgical literature as early as 1891.(9) We therefore were required to limit our cost analyses to the decades preceding 1890 when there may have be less ambiguity as to what was performed when a surgeon billed for a "simple" versus "radical cure" of a hydrocele.

Fee Tables and Specified urologic procedures: A total of 43 Fee Tables were identified that enumerated surgical fees for specific procedures that were performed in 18 states between 1818-1889. A total of 38/43 (88.4\%) fee tables described the fees for treatment of a hydrocele with curative intent. Over the 70 year study period, the description of the procedure appears to have remained largely unchanged and was limited to three (3) terms: "operation for hydrocele", "radical cure of hydrocele", or "injection of hydrocele". We found that urinary catheterization was listed in 33/43 (72.1\%) of fee tables and specified catheterization in the male versus female, for simple drainage versus dilation, and "initial" versus "subsequent". A total of 41/43 (95.3\%) fee bills were published by a state's or county's medical society and 2/43 (4.7\%) published by non-society journals.

Surgical Fees for Hydrocele "radical cure": A total of 29/38 (76.3\%) fee tables listed a low and high range for the recommended fee for the surgical care of the hydrocele and 9/38 (23.7\%) listed a 'flat' fee (data not shown). We analyzed the trend in the lower versus higher range prices over time and chose to include the 'flat' fee price with the lower range data. We found that over the 70 year study period there was an insignificant increase in the low end fee pricing for hydrocele. The average low end fee in contemporary, inflationnon-corrected US dollars for the treatment hydrocele from $1818-1840$ was $\$ 18.4+/-17.94$ versus $\$ 28.70+/$ 36.83 from $1880-1890(p>.05)$.

The case of Dr. J.C. Hall and President Andrew Jackson. James Crowdhill Hall was a revered physician and medical leader of mid-19th century Washington D.C. Dr. Hall first evaluated and treated President Jackson for a "hydrocele" in 1831 and twice charged the 7th President $\$ 30.00$ for the "operation for the hydrocele". Fee tables from the Washington Medical Society of 1833 and 1837 do not specify the fees for 'simple' or "radical" hydrocele operations, though they did specify the fees for first time catheterization ( $\$ 5.00$ ) and the range charged for "lithotomy" of $\$ 40.00$ to $\$ 100.00 .(10,11)$ Contemporary tables that do list rates for hydrocele surgery include those of physicians from 1831 Hartford who charged $\$ 15.00$ for "radical cure" and in 1836 Pittsburgh where the prevailing charge was $\$ 20.00 .(12,13) \mathrm{A}$ surgical bill from Lowell Massachusetts of 1840 recommends the fee of $\$ 2.00$ for simple hydrocele drainage 
and $\$ 5.00$ for the "operation" while the charge in Macon, Georgia for hydrocele was $\$ 50.00 .(14,15)$

Surgical Billing for Urinary catheterization. Unlike hydrocele therapy, we considered that the technique of routine male urinary catheterization may be similar throughout the history of the republic. We therefore compared surgeon reimbursement from 1818-1850, 1851-1900, 1976-1985, and 1992-2020, first as contemporary charges, and then in 2020 US dollars. The surgical fees for a first encounter male urinary catheterization remained flat throughout the 19th century study period with an average price of $\$ 4.28+/-1.25$ from 1818-1950 compared to $\$ 4.75+/-5.62$ from 1851-1900 ( $p$-value 0.67). In comparison, during the pre-RVU based Medicare years of 1976 to 1984, the average (standard deviation) reimbursement for urinary catheterization was $\$ 22.93+/-5.65$. In the RVU-era, from 1992 to 2020, the average reimbursement for urinary catheterization was $\$ 18.16+/-1.11$. Adjusting to 2020 dollars, however, the reimbursement for urinary catheterization in
1818-1850, 1850-1900, 1975 to 1984, and 1992-2000 was $\$ 113.04+/-38.06, \$ 131.20+/-169.53, \$ 73.87+/-$ 2.38 , and $\$ 23.05+/-4.69$, respectively.

\section{DISCUSSION}

Our contemporary view of surgical reimbursement under Medicare is that payment for services is derived from RVUs multiplied by a geographic practice cost index value $(\mathrm{GPCl})$. Urologists are able to calculate their expected CMS reimbursement for any specified CPT code performed in any state. Throughout the history of the republic, however, surgical fees were in large part based on consensual levels established by local and state medical societies.(3,16-18) Data, however, that documents just what those pre-Medicare fees were and how they evolved over the history of American medicine has rarely been reported. This study allowed us to understand the billing behavior of physicians over the entire 19th century and then compare those to our era. We found that not only was President Jackson's physician,

\begin{tabular}{|l|l|l|l|l|l|l|l|l|l|}
\hline Year & Location & Low & High & Ref. & Year & Location & Low & High & Ref. \\
\hline 1818 & New Hampshire & $\$ 2$ & & 3 & 1875 & Chicago & $\$ 20$ & $\$ 50$ & 21 \\
\hline 1831 & Hartford, CT & $\$ 15$ & & 12 & 1879 & Los Angeles, CA & $\$ 25$ & $\$ 100$ & 21 \\
\hline 1836 & Pittsburg, PA & $\$ 20$ & & 13 & 1882 & Central District, IA & $\$ 20$ & $\$ 30$ & 17 \\
\hline 1841 & Macon, GA & $\$ 50$ & & 15 & 1882 & lowa Un. Med. Soc. & $\$ 15$ & $\$ 40$ & 17 \\
\hline 1848 & Philadelphia, PA & $\$ 5$ & $\$ 20$ & 22 & 1882 & Brooklyn & $\$ 20$ & $\$ 75$ & 23 \\
\hline 1848 & Allegheny Cnty PA & $\$ 20$ & & 24 & 1883 & Milwaukee & $\$ 25$ & $\$ 50$ & 20 \\
\hline 1850 & San Francisco, CA & $\$ 100$ & $\$ 200$ & 25 & 1883 & Des Moines, IA & $\$ 15$ & $\$ 100$ & 17 \\
\hline 1852 & Philadelphia, PA & $\$ 5$ & $\$ 10$ & 26 & 1886 & Polk County, IA & $\$ 10$ & $\$ 25$ & 17 \\
\hline 1855 & New York NY & $\$ 5$ & $\$ 20$ & 27 & 1886 & Scott County, IA & $\$ 10$ & $\$ 25$ & 17 \\
\hline 1855 & Sacramento, CA & $\$ 50$ & $\$ 100$ & 27 & 1889 & Kansas City, MO & $\$ 25$ & $\$ 100$ & 28 \\
\hline 1858 & Hamden, MA & $\$ 5$ & $\$ 10$ & 29 & 1891 & Average US & $\$ 20$ & $\$ 50$ & 30 \\
\hline 1859 & Louisville, KY & $\$ 25$ & $\$ 50$ & 31 & 1891 & North Parma, NY & $\$ 10$ & $\$ 25$ & 30 \\
\hline 1860 & New York NY & $\$ 20$ & $\$ 60$ & 16 & 1891 & Chattanooga, TN & $\$ 25$ & $\$ 50$ & 30 \\
\hline 1862 & Madison, IN & $\$ 50$ & & 32 & 1891 & Kershaw County, IA & $\$ 15$ & $\$ 25$ & 30 \\
\hline 1862 & Knightstown, IN & $\$ 10$ & & 33 & 1891 & Kansas City, MO & $\$ 25$ & $\$ 100$ & 30 \\
\hline 1864 & Sullivan, IN & $\$ 25$ & $\$ 50$ & 34 & 1892 & Sullivan, IN & $\$ 25$ & $\$ 50$ & 34 \\
\hline 1864 & Philadelphia, PA & $\$ 25$ & & 27 & 1892 & Chicago, IL & $\$ 50$ & $\$ 200$ & 35 \\
\hline 1868 & Milwaukee, WI & $\$ 10$ & $\$ 25$ & 20 & 1894 & Baltimore, MD & $\$ 10$ & $\$ 50$ & 36 \\
\hline
\end{tabular}

All Known Fee Tables for "radical" operative therapy for hydrocele in 19th century America cited in manuscript. Where no low or high fee range was given, the provided fee was placed in the "low" column. Not included: 1898 Fee of the Medical Society of San Francisco for the "radical cure of hydrocele" of $\$ 200$ (Ref. 21). Abbreviations: Ref.:Reference 
Dr. James C. Hall, reasonably fair and appropriate with the fees charged for his services, but that physician fees throughout the 19th century were remarkably unchanged. The pricing of medical fees by physicians took in account several factors including self-perceived value of a service, initial versus subsequent care, simple versus complicated procedures, and risk, all of which are incorporated into RVU billing. Pricing in the 19th century was different in that physicians also took into account the time of day, road conditions, travel time, financial status of the patient, and the generally low rate of payment3. Overcharging was negatively perceived and cast skepticism on the quality of care.

We found that Dr. Hall's charges of $\$ 5$ for an initial consultation, $\$ 2$ for a subsequent consultation, and $\$ 30$ for a hydrocele operation were all in line with prevailing charges recommended by the Society despite the status of Dr. Hall's famous patient. We also found that the "operation", or what many over the 1818-1898 period called a "radical cure" for hydrocele was not what is known today as a "hydrocelectomy". Most 18th-19th century physicians viewed hydrocele care as either a simple drainage via an incision and stylet (or 'seton'), or "operation", that is, 'hydrocelotomy' plus injection of scarifying agents and long term drains. Dr. Hall's "operation" on Jackson most likely was the latter. Thus, for our analysis, we were not able to compare hydrocele costs from the 19th century with those of our current era because of the different nature of the procedure.

For a long term model comparison of urologic costs, therefore, we analyzed the fees for male urinary catheterization which we conjectured was performed similarly to an early 19th century physician as it is in a 21 st century emergency room. We found that, in 2020 US dollars, a simple catheterization in the early 19 th century would be charged on average about $\$ 120$. By 2020, the Medicare rate for physician's services for the simple catheterization had dropped to $\$ 20$. Even at this level of granularity, one may surmise that 19th century physicians charged higher rates, at least 5 fold higher, than physicians are reimbursed now for the same procedure. Physicians may have chosen to demand higher average fees in historical times to compensate for the then notoriously low rate of reimbursement. . Physicians in the Medicare era may be reimbursed at the lowest rates in history but may make up for the difference with increasing services rendered.

Medical societies realized even in pre-Revolutionary America that some patients had limited means to pay fees. The concept of a 'slide fee scale' had become codified in 19th century fee tables, "establishing a minimum and maximum charge...giving each member the liberty of deciding for himself on any sum between the highest and lowest designated".(19) We found that the majority of fee tables in the study utilized the sliding scale and were remarkably consistent across the country, though they rose over time. Mid-century surgeons in Philadelphia charged $\$ 5-20$ for hydrocele drainage and scarification which rose to $\$ 10-50$ in 1890 Baltimore. The discretionary nature of physician billing, to some, reflected the self-perceived quality of the services provided, a concept somewhat anathema to the RVU era of the same price for low or high quality procedures.

We recognize many limitations with our analysis, namely that the paucity of data on billing in the 19th century may not make up a legitimate set of numbers for statistical analysis. Our data sets are derived from the current digitalized landscape and may not reflect the unknown and potentially unlimited texts yet to be available through computer based searching. Similarly, the only bills we analyzed of Dr. Hall, the original subject of the analysis, were preserved by the federal government and do not reflect a larger pattern of billing of non-Presidential patients.

Still, ours is the first study, of which we are aware, that documents historical billing fees over the course of American history for any medical let alone urological procedures and places into perspective the diminished financial returns on medical care, despite a presumed increase in quality, and the education required to deliver quality care. The study may also suggest whether a well self-regulated and transparent physician-driven fee table as a basis for quality-focused surgical care should be revisited.

\section{CONCLUSION:}

Surgical billing in the 19th century was included as a direct doctor to patient discretionary charge, based on published medical society fee tables, taking into account case complexity, time, experience required, and travel. Charges for hydrocele were stable over the 19th century and reflected the flat, non-inflationary period of the gold standard of that time. Dr. James Hall was a prescient leader of Washington, DC medicine and appeared to bill President Andrew Jackson for hydrocele therapy that was consistent with prevailing charges. Reimbursement for male urinary catheterization, however, appears to 
have decreased, correcting for inflation, from early 19th century highs to their lowest levels in US history by 2020.

\section{REFERENCES}

1. Hsiao WC, Braun P, Dunn D et al: Resource-based relative values. An overview. JAMA 1988; 260: 2347.

2. Schroeder SA: Personal reflections on the high cost of American medical care: many causes but few politically sustainable solutions. Arch Intern Med 2011; 171: 722.

3. Crombie J: Fee Table of the Southern District of the New Hampshire Medical Society 1818; p 4.

4. Andrew Jackson papers, 1775-1874, Library of Congress.

5. Medicare Learning Network: How to Use the Searchable Medicare Physician Fee Schedule (MPFS) 2020; ICN 901344:

6. History of Medicare Conversion Factors. American Academy of Pediatrics (www.ama-assn.org/system/ files/2021-01/cf-history.pdf)

7. American Medical Association: Medicare RBRVS: the physicians' guide 1993;

8. Earle J: An Account of the Method of Obtaining a perfect of Radical Cure of the Hydrocele by Means of a Seton. In: The Chirurgical Works of Percival PottAnonymous London: Wood \& Innes 1808; p 3.

9. Brokaw AVL: Report of Cases. Saint Louis Courier of Medicine 1891; 5: 110.

10. Fee Table. In: Regulations and System of Ethics of the Medical Association of WashingtonAnonymous Washington: Charles H. Barron 1833.

11. Medical Ethics. In: Regulations and System of Ethics of the Medical Association of Washington, D.C.Anonymous Washington: Jacob Gibbon, Jr. 1837.

12. Russell GW: Fee Table of 1831. In: Sketches of Physicians in Hartford. Hartford: Case, Lockwood, \& Brainard, 1890.

13. Addison W, Agnew J, Armstrong CL: A Fee Bill Sixty Years Old. Pennsylvania Medical Journal 1897; 28: 288.

14. Smith JVC: Lowell Medical Association. In: The American Medical Almanac of 1840. Boston: Marsh, Capon, Lyon, and Webb 1840; $\mathrm{p} 2$.

15. Curtis A: Macon Medical Fee Bill. Botanico-Medical Recorder 1841; 9: 334.

16. Baker AH, Thacker JA: Fee Bill of the Medico-Surgical Society of New York, 1860. Cincinnati Medical and Surgical News 1862; 3: 148.

17. Lothrop $\mathrm{CH}$ : Fee Bills Adopted by Medical Societies in Different Parts of the State. In: Medical and surgical directory of the state of lowa for 1886-1887. Clinton, IA: Allen, Steam Printing, Binding 1886.

18. Bradbury S: Fee Table of the Chicago Medical Society. In: The cost of adequate medical care. MM Davis (Ed.). Chicago: University of Chicago Press 1937.
19. Transactions of the Medical Society of the County of Albany. Albany, NY: Charles Van Benthuysen 1872.

20. Frank LF: Fee Bill Adopted by the Milwaukee County Medical Society. In: The Medical History of Milwaukee, 1834-1914. Milwaukee: Germania Publishing 1915.

21. Felton KC, Smith FW, Dunlop GH: Appendix: The California Survey. In: Report of the Social Insurance Commission of the State of California. Sacramento: California State Printing Office 1919.

22. Meigs CD: Fee Bill. In: Summary of the transactions of the College of Physicians of Philadelphia, Philadelphia: William F. Geddes 1848; $p 2$.

23. Hopkins GG: Fee Bill of the Medical Society of the County of Kings. In: The proceedings of the Medical Society of the County of Kings. Brooklyn, New York. Brooklyn: Office of Publication 1882.

24. Baker AH, Thacker JA: Fee Bill of Medical Association of Allegheny County, PA. Cincinnati Medical and Surgical News 1862; 3: 83.

25. Dimon T, Harris SR, Grover WA: By-Laws and Fee Bill of the San Francisco Medical Society. San Francisco: California Daily Courier 1850.

26. College of Physicians of Philadelphia: Charter, ordinances and by-laws of the college of physicians of Philadelphia. Philadelphia: T.K. and P.G. Collins 1851.

27. College of Physicians of Philadelphia: Charter, ordinances and by-laws of the college of physicians of Philadelphia. Philadelphia: T.K. and P.G. Collins 1864.

28. Lanphear E: Kansas City Fee Bill. Kansas City Medical Index 1889; 10: 338.

29. Adams N, Chapman TL, Otis GA: Tariff of Fees. In: Rules and Regulations of the Hampden District Medical Society Springfield: Samuel Bowles 1858.

30. Taylor JJ: The Physician as a Business Man. Philadelphia: The Medical World 1892.

31. Miller H, Powell L, Bell TS: A Scale of Fees Adopted by the Physicians of Louisville. Cincinnati Medical and Surgical News 1862; 3: 53.

32. Hendricks JG, Conner WJ, Kunkler GA: Bill of Charges, Madison, Indiana. Cincinnati Medical and Surgical News 1862; 3: 377.

33. Canadry NH: Fee Bill of the Union Medical Society, Knightstown, Indiana. Cincinnati Medical and Surgical News 1862; 3: 108.

34. Maple JB: A Medical History of Sullivan County, Indiana. Sullivan, Indiana: Sullivan Union Press 1936.

35. Robison JA, Thackeray WT, Doering EJ: Fee Table Chicago Medical Society. Chicago Medical Journal 1892; 3: 419.

36. Johnson RW: Amendments to the Constitution: Report of Committee on Revision of the Fee Table. In: Transactions of the Medical and Chirurgical Faculty of the State of Maryland, 96th ed. Baltimore: Griffen, Curley \& Company 